\title{
Integrating Intangible Assets within Collaborative Networks Performance Management
}

\author{
Juan-Jose Alfaro-Saiz, Raul Rodriguez-Rodriguez, and Maria-Jose Verdecho \\ Universitat Politècnica de Valencia, Departamento de Organización de Empresas, \\ Camino de Vera sn, 46022 Valencia, Spain \\ \{jalfaro, mverdecho\} @omp.upv.es, \\ raurodro@upvnet.upv.es
}

\begin{abstract}
It is out of question the importance that intangible assets have acquired during the last decade. The management of such intangible assets is getting more and more the attention of both academics and professionals. It is aimed, through the application of different models and tools, to measure and manage them in order to achieve competitive advantages that will lead to better business sustainability. In this sense, organizations, taking into account both the intra and the inter-organizational level, must be able to seek and find the most efficient ways of integrating their intangible assets within their performance management systems. Up to now, most of the existing scientific works are focused on managing the intangible assets at the intra-organizational context. The key role that collaborative networks has got at the business ecosystem nowadays, and will have in the future, demands to define frameworks that deal with intangible assets management at the inter-enterprise context. This paper describes an approach of how to integrate intangible assets within collaborative networks. It follows a collaborative business processes approach, taking into account both the global ambit of the collaborative network as well as the individual enterprises that comprise the collaborative network ambit. The model includes a simplified and agile intangible assets management model, which might be used as a reference framework for collaborative networks in this field.
\end{abstract}

Keywords: Intangible assets, Collaborative networks, Performance management.

\section{Introduction}

From over a decade ago, concepts such as intellectual capital, intangible assets, knowledge management, intellectual assets, etc., have emerged in the literature significantly. Lots of works, projects and publications have focused on researching all these concepts from different areas and under different views. The idea that resides in this effort is clear: to try to measure and manage everything that adds value to the organization, but given its intangible nature, all these concepts have been long overlooked by both academics and professionals. Now, what is meant by intangible assets? A simple but comprehensive definition is provided by [1], "Intangible assets are a firm's dynamic capability created by core competence and knowledge resources, including 
organization structure, employee expert skills, employment centripetal force, R \& D innovation capability, customer size, recognizable brand, and market share". Thus, intangible assets and intellectual capital can be understood as synonyms, or what it is the same: the intellectual capital is composed of all the intangible assets of an organization.

The intangible nature is reflected on their influence for value creation, competitive advantages generation and economic benefits [2], [3], [4]. Thus, a company's capability to create value depends on its ability to implement strategies that respond to market opportunities by exploiting their internal resources and capabilities [5].

Currently, in the knowledge society, the focus is directed to the intangible assets. This reflects the belief that intangible assets are a fundamental resource of corporate growth and organizations need to put into work procedures for managing them [6].

In this sense, this work has been focused over time on various tasks: firstly to clarify, as far as possible, all the concepts used (although up to date there is not any standardization neither of definitions nor concepts); moreover, in developing models and tools to measure and manage in the best possible way such intangible assets; and, ultimately, in creating the mechanisms to incorporate their value to traditional tangible assets, thereby achieving to define the overall value of an organization. Initially, the work is focused on the intra-organizational (the vast majority of the work done is exclusively in this field) and, rapidly, it is seen some works that attempt to address the inter-organizational field. This paper describes an approach of how to integrate intangible assets within collaborative networks. The approach includes a simplified and agile intangible assets management model, which might be used as a reference framework for collaborative networks in this field.

\section{Intangible Assets Management}

Nowadays, it is completely accepted that there is a relationship between intangible assets and the performance of an organization. Thus, organizations able to measure and manage intangible assets will be in a better position to improve their performance. Although the important influence that intellectual capital (IC) possesses on business performance is greatly acknowledged, few studies have been devoted to demonstrating how the different intellectual capital components influence performance and what specific performance dimensions are affected [7]. However, how the IC is related to the organization's performance? Some authors have worked on this subject although certainly with disparate and unconnected results [8], [9], [10], [11].

On the other hand, other frameworks are focused on the intangibles related to the defined strategies such as [12]. This framework identifies the need of linking the intangible assets with the strategy of the company; this model proposed the identification of the strategic objectives of the company and the critical intangible assets related to each of these strategic objectives. Other studies have focused on defining methods that take into account the relationships between intangible assets, tangible assets and strategic perspectives of the organization [13]. In this sense, an organization should try to understand which of its both tangible assets (TA) and intangible assets (IA) influence the sustainability of competitive advantage the most [14]. 
Moreover, it is important to note also that IA are affected by various factors, which should be monitored to some extent. Thus, according to [1], the factors affecting intangible assets can be classified into six categories: intangible capital, ownership structure, corporate governance, firm characteristics, industry characteristics, and reactions of analysts and customers. In turn, other authors such as [15] proposed that the variation in value of an intangible asset is explainable by the appreciation or depreciation of its context (market forces, speculation, problems with unions, and competition risks such as new technology, new regulations or new imports). This author suggests that the effective (or ineffective) use of intangible assets also affects value as part of a dynamic system with internal variations and exchanges within the context.

Following the above, we must tackle several problems; firstly, the actual measurement of intangible assets, then the management, and, finally, to find out how these assets influence on performance and how to maximize the value creation. The main difficulty is to integrate the intangible assets with the tangible assets within a performance management system. Furthermore, this problem becomes more complex when the scope of the work is at the inter-organizational context, as it is a collaborative network.

It is in this collaborative network area where less it has been worked when managing intangible assets, and therefore, where greater efforts must be made. Some authors have developed frameworks to measure and manage the performance in collaborative areas [16], [17], [18], [19], [20], [21], [22] but they have not dealt with how to integrate intangible assets. The most important points that need further attention to integrate intangible assets into the performance management systems used in the collaborative networks field are the following:

- There is a set of factors (Collaborative factors) that influence to the collaborative network performance and, therefore, has a direct or indirect impact on intangible assets. Among others it may be mentioned the following factors: trust, equity, coherence, visibility, contradictory objectives, or communication issues [17]. This factors need to be properly managed in order to achieve an effective collaboration. If these factors are not managed, it is possible that this type of relationship can result in problems such as internal and external conflicts, loss of customer satisfaction and cost increase [23,24].

- Establish the linkage between the tangible and the intangible assets of the CN. This is such a difficult task, but it needs to be done in order that $\mathrm{CN}$ decisionmakers will be able to clearly know to what extent the achievement of a certain degree of intangible assets within the $\mathrm{CN}$ is impacting over the fulfilment of the CN's strategic objectives [6].

- Intangible assets are also affected by a number of "structural" factors that may distort their value or hide the true incidence of these on the collaborative network performance. A classification of these factors is the following: intangible capital, ownership structure, corporate governance, firm characteristics, industry characteristics, and reactions of analysts and customers [1].

- Nowadays, individual enterprises take part in several supply chains/CNs and, therefore, it is very likely that some of these CNs will have contradictory objectives. This fact has actually a decisive impact on intangible assets, as if they help to achieve the $\mathrm{CN}$ strategic objectives and, at the same time, the achievement of such strategic objectives do increment or improve the IA, the question is: what happens from an indi- 
vidual point of view when there are conflictive targets between different CNs in which a particular company is involved? How to find a good "coherence" level between objectives, levels (individual - $\mathrm{CN}$ ) and intangible assets for achieving both a local and a global performance improvement?

The following section presents an approach to integrate intangible assets within collaborative networks following a Collaborative Business Processes approach, taking into account both the global and the individual ambit. The model includes a simplified and agile intangible assets management model, which might be used as a reference framework for collaborative networks.

\section{Integrating Intangible Assets within Collaborative Networks Performance Management}

In the previous section, we have described some of the principal points on which to pay attention when trying to build a framework able to integrate intangible assets within collaborative networks performance management. Figure 1 shows a generic framework approach, which illustrates the steps required for such integration, and Figure 2 shows the intangible assets management model.

The Generic framework simply establishes that there are two main phases (Phase I: Strategic framework definition, and Phase II: Processes framework definition), which works on three levels (Collaborative Network, Processes and Individual); because the collaborative factors are affecting to the $\mathrm{CN}$ performance, they must be taken into account in both phases. Moreover, it is absolutely essential that there is an adequate coherence degree between levels.

The Intangible Assets Management model establishes the structure and relationships between different elements of performance measurement/management to be used: Intangible/Tangible assets, Objectives, New intangible/intangible assets and key performance indicators (KPIs). Furthermore, as justified in the previous section, there are some structural factors affecting intangible assets, which therefore must be taken into account. As in the Generic framework, elements are structured in the same three levels (Collaborative Network, Processes and Individual).

Next, it is defined each of the elements used:

- Assets: it is any resource, both tangible and intangible, which possesses an organization (or $\mathrm{CN}$ single enterprise) or it would be appropriate to posses, and which shall be used when achieving each objective. This paper only focuses on the intangible assets.

- Objectives: They serve to define the desired result and, therefore, the objectives are something that can be evaluated or tested.

- New assets: all the resources, tangible or intangible, which are generated when achieving a certain objective. For example, can be the result of achieving a goal, both creating a new asset not previously available within the organization (by generating it or acquiring it in the market), or the increase in value of a particular asset, which already had the organization. Identification of new assets helps to establish which the direct and concrete results arising from the achievement of each goal are. This paper only focuses on the intangible assets. 
- Key performance indicators: they are elements or factors, which characterize and identify one aspect susceptible of measurement in order to evaluate or establish control over such area. If the nature of the intangible asset is quantitative, its measurement is performed; on the other hand, if it is qualitative, it is necessary to proceed to its valuation. KPIs will be established on the Assets, New assets and Objectives.

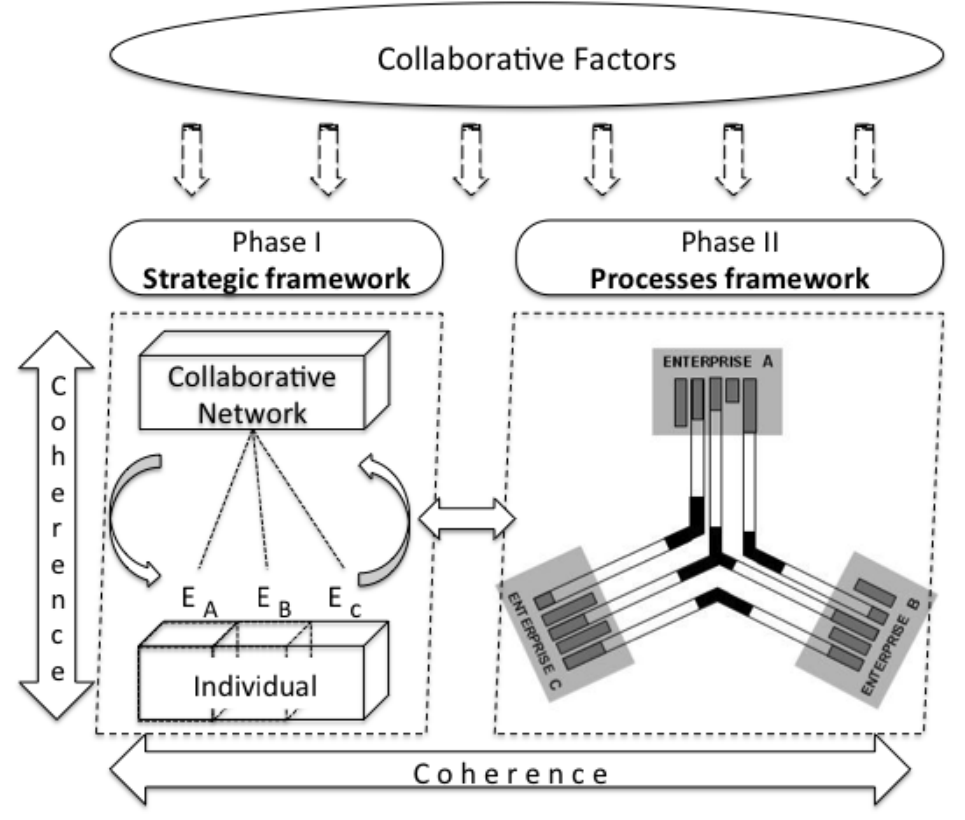

Fig. 1. Generic framework approach

Below, it is described the implementation methodology.

Step A: Business entity conceptualization

At this stage, it is clearly established how the Collaborative Network is made, what its critical business processes are, which activities are related to each business or organization, and finally, the collaborative factors that affect or might affect to the $\mathrm{CN}$ performance (at all levels) are identified.

Step B: Performance requirements definition

After the business entity has been conceptualized, all the performance measurement elements (Intangible assets, Objectives and KPIs) are defined. This shall be done in two phases (see Figure 1) and three levels $(\mathrm{CN}$, Processes and Individual): 
Collaborative Network

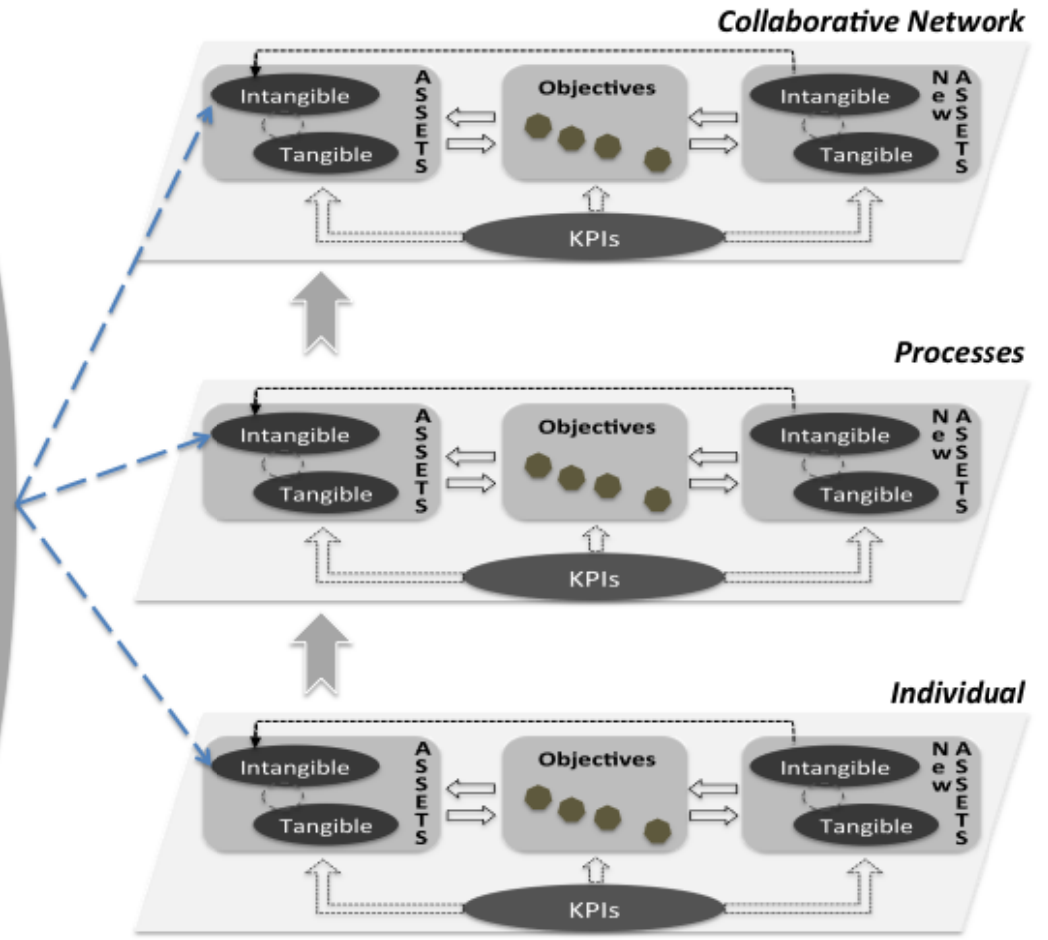

Fig. 2. Intangible assets management model

- Phase I: Strategic framework development. The order between levels will always be: CN, Processes and finally, Individual level. Firstly Objectives are defined, identifying then the intangible assets that will be needed in order to achieve the Objectives. Some of them may be provided directly by the CN but others do not, therefore, the latter will be acquired from outside the business entity. The following is an analysis of possible new intangible assets that may arise as a result of achieving the defined objectives, and how to integrate them into the business entity. Later, the identification and analyses of the main Structural factors that affect or may affect the intangible assets (and therefore should be monitored and taken into account) is carried out. Finally, the definition of the KPIs that help to measure and manage the items is done (see Figure 2).

- Phase II: Processes framework development. This phase tries to make a projection of all the performance requirements defined in the previous step over the main processes or critical processes. In this sense, it is possible to find some new performance elements but they will always be consistent with those defined in the previous level. Finally, the projection process is repeated, but this time at the individual level, although, at this level, each $\mathrm{CN}$ partner carries out internally such a projection process. Obviously, there should be a clear consistency with the performance measurement elements defined above at the processes level. 


\section{Step C: Analysis and monitoring KPIs}

Once it has been operated, the Intangible assets management model must perform an analysis of the KPIs results. By doing this, it will be possible to carry out and establish the correspondent conclusions.

\section{Conclusions}

In recent years, intangible assets are under a deep analysis. Academics and practitioners are developing a lot of work and effort to identify, integrate and manage them. Most of the works have focused on the intra-organizational context, and efforts should be also directed toward the inter-organizational context.

This contribution has analysed the problem of integrating intangible assets within a Collaborative Network. In particular, it has focused on those intangibles assets that help to improve the performance of a $\mathrm{CN}$ and its associated business processes. A Generic framework as well as an Intangible assets management model that allows integrating intangible assets within collaborative networks performance management has been introduced. This work is still under development and will be expanded and tested practically on various $\mathrm{CN}$ to refine those aspects susceptible to be improved.

Acknowledgements. This work has been developed within the research project called "Integration of the sustainability indicators within industrial supply chains strategy by applying mathematical techniques (SP20120890)" funded by the Universitat Politècnica de València.

\section{References}

1. Tsai, C.-F., Lu, Y.-H., Yen, D.: Determinants of intangible assets value: The data mining approach. Knowledge-Based Systems 31, 67-77 (2012)

2. Edvinsson, L., Malone, M.S.: Intellectual Capital, Realising your company's true value by finding its hidden brainpower. Harper Collins Publishers, Inc., New York (1997)

3. Kianto, A., Hurmelinna-Laukkkanen, P., Ritala, P.: Intellectual Capital in service and product oriented companies. Journal of Intellectual Capital 11(3), 305-325 (2010)

4. Maditinos, D., Chatzoudes, D., Charalampos, T., Theriou, G.: The impact of Intellectual Capital on firm's market value and financial performance. Journal of Intellectual Capital 12(1), 132-151 (2011)

5. Penrose, E.T.: The theory of the growth of the firm. John Wiley, New York (1959)

6. Rodriguez-Rodriguez, R., Alfaro-Saiz, J.-J., Verdecho, M.-J.: A Review on Intellectual Capital Concepts as a Base for Measuring Intangible Assets of Collaborative Networks. In: Camarinha-Matos, L.M., Pereira-Klen, A., Afsarmanesh, H. (eds.) PRO-VE 2011. IFIP AICT, vol. 362, pp. 41-47. Springer, Heidelberg (2011)

7. St-Pierre, J., Audet, J.: Intangible assets and performance: Analysis on manufacturing SMEs. Journal of Intellectual Capital 12(2), 202-223 (2011)

8. Wang, W.-Y., Chang, C.: Intellectual capital and performance in causal models: evidence from the information technology industry in Taiwan. Journal of Intellectual Capital 6(2), 222-236 (2005) 
9. Cohen, S., Kaimenakis, N.: Intellectual capital and corporate performance in knowledge intensive SMEs. The Learning Organization 14(3), 241-262 (2007)

10. Ittner, C.D.: Does measuring intangibles for management purposes improve performance? A review of the evidence. Accounting and Business Research 38(3), 261-272 (2008)

11. Boj-Viudez, J.: Metodología para la identificación, selección, medición y gestión de los intangibles en una organización en el ámbito de un sistema de medición del rendimiento: Aplicación a un centro de investigación universitario. Doctoral Thesis (2011)

12. MERITUM Guidelines. Guidelines for Managing and Reporting on Intangibles, Madrid (2002)

13. Jhunjhunwala, S.: Monitoring and measuring intangibles using value maps: Some examples. Journal of Intellectual Capital 10(2), 211-223 (2009)

14. Greco, M., Cricelli, L., Grimaldi, M.: A strategic management framework of tangible and intangible assets. European Management Journal 31, 55-66 (2013)

15. Axtle-Ortiz, M.-A.: Perceiving the value of intangible assets in context. Journal of Business Research 66, 417-424 (2013)

16. Alfaro, J.J., Ortiz, A., Rodríguez, R.: Performance measurement system for Enterprise Networks. International Journal of Productivity and Performance Management 56(4), 305-334 (2007)

17. Alfaro-Saiz, J.J., Rodriguez-Rodriguez, R., Ortiz Bas, A., Verdecho, M.J.: An information architecture for a performance management framework by collaborating SMEs. Computers in Industry 61, 676-685 (2010)

18. Gaiardelli, P., Saccani, N., Songini, L.: Performance measurement of the after-sales service network - Evidence from the automotive industry. Computers in Industry 58, 698-708 (2007)

19. Gruat, F.A., La Forme, V., Campagne, J.P.: A Framework to analyse Collaborative Performance. Computers in Industry 58, 687-697 (2007)

20. Bititci, U.S., Mendibil, K., Martinez, V., Albores, P.: Measuring and managing performance in extended enterprises. International Journal of Operations \& Production Management 25(4), 333-353 (2005)

21. Folan, P., Browne, J.: Development of an extended enterprise performance measurement system. Production Planning \& Control 16(6), 531-544 (2005)

22. Angerhofer, B.J., Angelides, M.C.: A model and a performance measurement system for collaborative supply chains. Decision Support Systems 42, 283-301 (2006)

23. Kampstra, R.P., Ashayeri, J., Gattorna, J.L.: Realities of supply chain collaboration. The International Journal of Logistics Management 7(3), 312-330 (2006)

24. Bititci, U.S., Turner, T., Mackay, D., Kearney, D., Parung, J., Walters, D.: Managing synergy in collaborative enterprises. Production Planning and Control 18(6), 454-465 (2007) 